Check for updates

Cite this: J. Mater. Chem. B, 2021 9, 7023

Received 12th February 2021 Accepted 15th April 2021

DOI: $10.1039 / d 1 t b 00300 c$

rsc.li/materials-b

\section{DNA-based ribonuclease detection assays}

\author{
Arun Richard Chandrasekaran (D)
}

Ribonucleases are useful as biomarkers and can be the source of contamination in laboratory samples, making ribonuclease detection assays important in life sciences research. With recent developments in DNA-based biosensing, several new techniques are being developed to detect ribonucleases. This review discusses some of these methods, specifically those that utilize G-quadruplex DNA structures, DNA-nanoparticle conjugates and DNA nanostructures, and the advantages and challenges associated with them.

\section{Introduction}

Ribonucleases (RNases) are involved in many biological processes including neurotoxicity, genome replication and maintenance, angiogenic activity, immune-suppressivity and antitumor activity. ${ }^{1}$ In retroviruses such as HIV1, an RNase $\mathrm{H}$ activity associated with the viral reverse transcriptase is required for replication, making RNase $\mathrm{H}$ inhibitors potential drugs for AIDS. ${ }^{2}$ Another common ribonuclease, RNase A, is found in nearly all organisms and is important for cellular RNA metabolism. ${ }^{3}$ RNase A has been extensively studied as a model system to understand protein stability and enzymatic

The RNA Institute, University at Albany, State University of New York, Albany, NY 12222, USA. E-mail: arun@albany.edu

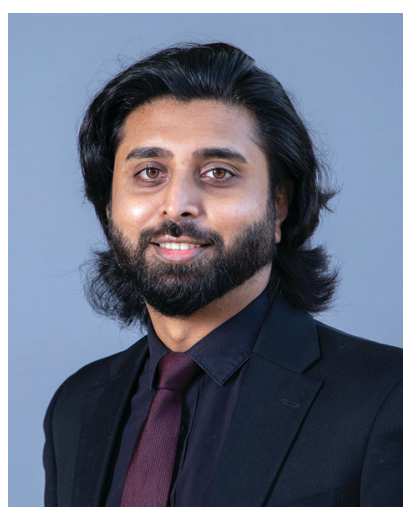

Arun Richard Chandrasekaran is a research scientist at The RNA Institute in the University at Albany, State University of New York (SUNY) at Albany. $\mathrm{He}$ received his BSc in Zoology from The American College (Madurai, India), MTech in Nanoscience from the University of Madras (Chennai, India) and a PhD in Chemistry from New York University, where he worked with Arun Richard Chandrasekaran Prof. Nadrian Seeman on self-
assembled DNA nanostructures. Arun Richard Chandrasekaran Prof. Nadrian Seeman on self-
assembled DNA nanostructures. His current research focuses on creating functional DNA devices for applications in biosensing, drug delivery and molecular computation. He is keen on science communication, has written for the magazine The Scientist, and runs the blog Stranded. mechanisms ${ }^{4}$ and the cytotoxic activity of RNase A makes it potentially useful in cancer treatment. ${ }^{5}$ RNases are also likely biomarkers for neoplastic diseases such as pancreatic cancer and in cystic fibrosis. ${ }^{6}$ In a laboratory setting, RNases are useful in some molecular biology protocols, but can also degrade biological RNA samples. Detection of RNases and their inhibition have therefore become increasingly important (Fig. 1), spurring the development of various RNase detection assays.

DNA has recently found use as a self-assembling material for applications in biosensing, drug delivery, molecular computation and structural analysis. ${ }^{7}$ Several DNA-based biosensing methods have been developed for detecting a variety of biomolecules such as DNA, ${ }^{8}$ RNA, ${ }^{9}$ antigens, ${ }^{10}$ and antibodies, ${ }^{11}$ as well as environmental sensing such as changes in $\mathrm{pH},{ }^{12}$ temperature ${ }^{13}$ and ionic conditions. ${ }^{14}$ Such DNA-based strategies have also been developed for detecting different types of RNases. ${ }^{15}$ Some of the traditional RNase detection assays include renaturation gel assays, ${ }^{16}$ highperformance liquid chromatography (HPLC) ${ }^{17}$ and colorimetry. ${ }^{18}$ To overcome limitations such as complexity, high-cost and low sensitivity, DNA-based approaches using catalytic hairpin assembly, ${ }^{19}$ gold nanoparticle conjugates, ${ }^{20}$ magnetic nanoparticles $^{21}$ and DNA walkers ${ }^{22}$ have been developed, some of which are discussed in this review.

\section{Ribonuclease detection strategies}

Typical RNase detection assays use the action of RNases on nucleic acid complexes to generate a signal. For example, RNase $\mathrm{H}$ cleaves an RNA strand that is part of a DNA:RNA hybrid duplex, and RNase A cleaves single stranded RNA molecules (Fig. 1a). These events are combined with a signal producing interaction. Nucleic acid complexes have been used in combination with cationic water-soluble polythiophene derivatives, ${ }^{23}$ DNA polymerase, ${ }^{24}$ DNAzymes, ${ }^{25}$ graphene oxide nanosheets, ${ }^{26}$ 
a
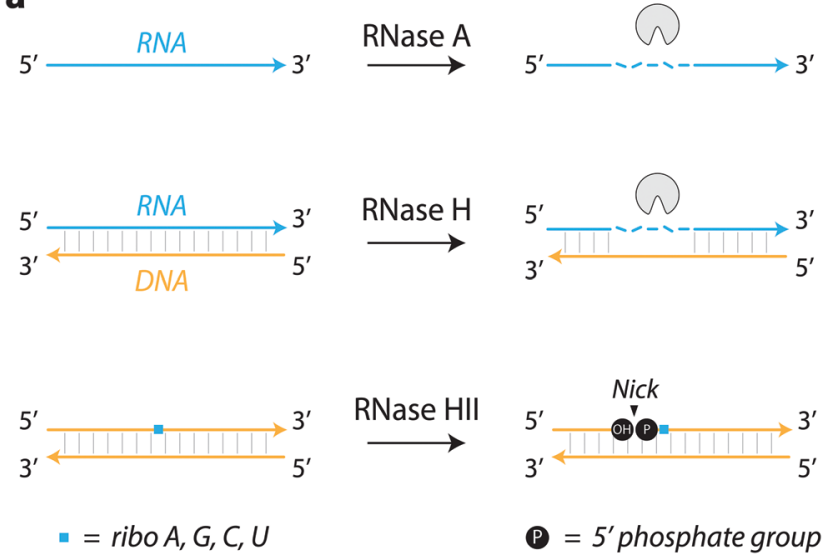

b

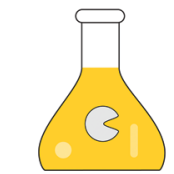

Sample contamination

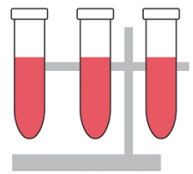

Biomarkers

specific ligands. One such example is $N$-methyl mesoporphyrin IX (NMM), an anionic porphyrin that selectively binds to G-quadruplexes and not single stranded, duplex or triplex structures. ${ }^{36} \mathrm{Qu}$ and co-workers designed a DNA:RNA hybrid duplex substrate where the DNA strand contains a G-quadruplex forming sequence (Fig. 2a). ${ }^{28}$ The ligand NMM was added to this solution, but exhibits weak fluorescence. In the presence of RNase H, the RNA strand of the hybrid duplex is cleaved, releasing the G-rich DNA strand which folds into a quadruplex structure in the presence of monovalent ions. The NMM ligand present in the solution binds to G-quadruplex DNA, causing an increase in fluorescent signal. This assay was able to detect enzyme activity within 10 minutes with a limit of detection (LOD) of $0.2 \mathrm{U} \mathrm{ml}^{-1}$. In another study, Wang and coworkers used a similar strategy, but used terbium $\left(\mathrm{Tb}^{3+}\right)$ as the signal generating ligand (Fig. 2a). ${ }^{29}$ This assay had an LOD of $2 \mathrm{U} \mathrm{ml}^{-1}$. Further, the assay was highly specific to RNase $\mathrm{H}$ when tested against other enzymes such as uracil-DNA glycosylase (UDG), human 8-oxoguanine DNA N-glycosylase I (hoGG I), T4 polynucleotide kinase (PNK), and Dpn I (restriction enzyme from Diplococcus pneumoniae).

In a different strategy, Wang and coworkers created an RNase assay that included an amplification step for higher signal production. ${ }^{30}$ In this method, RNase $\mathrm{H}$ cleaves the RNA strand of a DNA:RNA hybrid duplex substrate, releasing a single stranded DNA (Fig. 2b). This DNA then binds to a portion of a hairpin that also contains a specific nicking enzyme cleavage site in the loop. On binding the DNA, the hairpin is opened, allowing the nicking enzyme $N b . B b v C I$ to cleave the nicking site. This releases the G-rich portion of the hairpin DNA that forms a G-quadruplex and binds with thioflavin $\mathrm{T}$ to provide a fluorescent signal. The DNA released after the nicking reaction is recycled to open other hairpins, thus generating an amplified signal. The LOD for this assay was estimated to be $0.03 \mathrm{U} \mathrm{ml}^{-1}$, and the group demonstrated that the assay works efficiently in $1 \%$ human serum.

Park and colleagues used the G-quadruplex-specific NMM ligand in combination with target-triggered catalytic hairpin assembly (CHA) to create RNase assays (Fig. 2c). ${ }^{19}$ In catalytic hairpin assembly, a single stranded DNA triggers the self-assembly

Table 1 Summary of different DNA-based RNase detection strategies

\begin{tabular}{|c|c|c|c|c|}
\hline Method & Readout & LOD & Assay time & Inhibitor screening \\
\hline \multicolumn{5}{|l|}{ G-quadruplex based assays } \\
\hline$N$-Methyl mesoporphyrin IX (NMM) $)^{28}$ & Fluorescence & $0.2 \mathrm{U} \mathrm{ml}^{-1}$ & $10 \mathrm{~min}$ & Ellipticine, ethidium bromide \\
\hline Terbium $^{29}$ & Fluorescence & $2 \mathrm{U} \mathrm{ml}^{-1}$ & $15 \min$ & Gentamycin, ethidium bromide \\
\hline Thioflavin $\mathrm{T}^{30}$ & Fluorescence & $0.03 \mathrm{U} \mathrm{ml}^{-1}$ & $65 \min$ & Gentamycin \\
\hline NMM/catalytic hairpin assembly ${ }^{19}$ & Fluorescence & $0.037 \mathrm{U} \mathrm{ml}^{-1}$ & $\sim 3 \mathrm{~h}$ & Oxoglaucine, ellipticine \\
\hline \multicolumn{5}{|l|}{ Nanoparticle based assays } \\
\hline AuNP/fluorophore ${ }^{20}$ & Fluorescence & $43 \mu \mathrm{U}$ in $10 \mu \mathrm{l}$ reaction & $1 \mathrm{~h}$ & None \\
\hline AuNP/EBMVC ${ }^{31}$ & Fluorescence & $0.013 \mathrm{U} \mathrm{ml}^{-1}$ & $2-3 \mathrm{~h}$ & None \\
\hline AuNP/DNAzyme ${ }^{32}$ & Fluorescence & $0.00847 \mathrm{U} \mathrm{ml}^{-1}$ & $2-3 \mathrm{~h}$ & Ellipticine \\
\hline AuNP/DNA walker ${ }^{22}$ & Fluorescence & $0.035 \mathrm{U} \mathrm{ml}^{-1}$ & $40 \min$ & $\begin{array}{l}\text { Ampicillin, kanamycin, gentamycin, } \\
\text { streptomycin sulfate }\end{array}$ \\
\hline \multicolumn{5}{|l|}{ DNA nanostructures } \\
\hline DNA tetrahedron/AgNC ${ }^{33}$ & Fluorescence & $3.41 \mathrm{U} \mathrm{ml}^{-1}$ & $30 \mathrm{~min}$ & None \\
\hline DNA tetrahedron/fluorophore ${ }^{34}$ & Fluorescence & $0.09 \mathrm{pg} \mathrm{ml}^{-1}$ & $1 \mathrm{~h}$ & None \\
\hline DNA nanoswitch ${ }^{35}$ & Gel electrophoresis & $0.02 \mathrm{U}$ in $10 \mu \mathrm{l}$ reaction & $1 \mathrm{~h}$ & Kanamycin \\
\hline
\end{tabular}




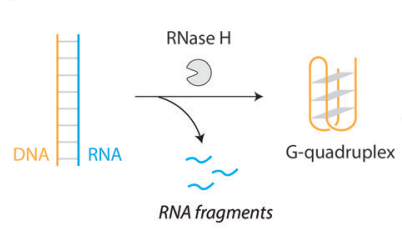

b

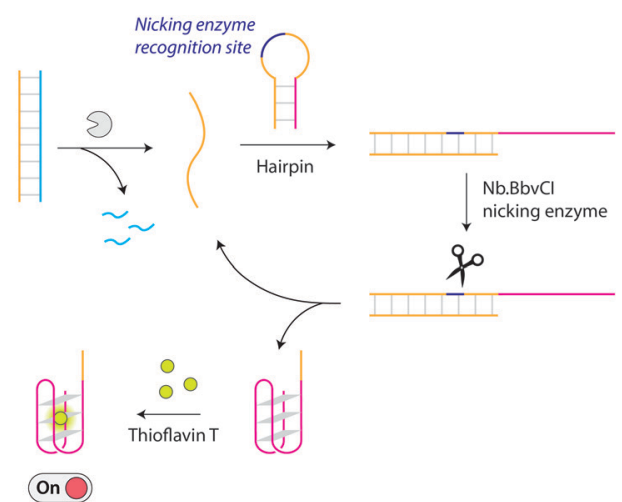

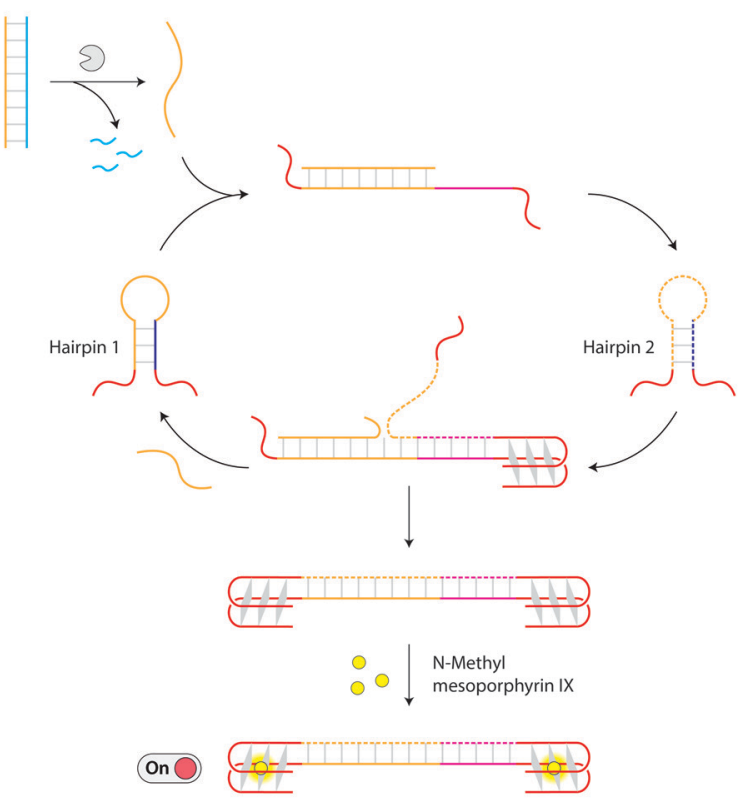

Fig. 2 G-quadruplex-based RNase assays. (a) G-quadruplex forming sequences released from DNA:RNA hybrid duplexes can bind to specific ligands and create a fluorescent signal. ${ }^{28,29}$ (b) Hairpin-mediated detection strategy includes a nicking enzyme to amplify the signal. ${ }^{30}$ (c) Catalytic hairpin assembly is used to generate multiple copies of G-quadruplex containing duplexes, producing an amplified detection signal. ${ }^{19}$

of two metastable hairpin DNA probes via toehold-mediated strand displacement, thus producing a large number of hybridized duplexes. ${ }^{37}$ In this CHA-based method, RNase H degrades the RNA in a DNA:RNA hybrid duplex substrate, releasing the DNA strand that binds to hairpin 1 via toehold based strand displacement. This reaction causes hairpin 1 to open and bind to hairpin 2, thus catalyzing hairpin assembly. This results in the production of a large number of duplexes with G-quadruplexes at the termini that can bind to NMM ligand and produce a fluorescent signal. With an LOD of $0.037 \mathrm{U} \mathrm{ml}^{-1}$, this assay was highly specific to RNase $\mathrm{H}$ when tested against DNase I, exonuclease I, exonuclease III, Hind III and UDG.

\subsection{Nanoparticle based assays}

The cleavage of RNA by RNases is exploited in nucleic acid-gold nanoparticle (AuNP) conjugates where the ends of DNA or RNA are tagged with fluorescent dyes. Reich and coworkers used this strategy to detect ribonucleases such as RNase $\mathrm{H}$ and RNase A. ${ }^{20}$ They used $13 \mathrm{~nm}$ AuNPs and conjugated them with RNA strands that are tagged with a fluorophore at the other end. The fluorescein-labeled RNA molecule in an intact conjugate exhibits very low fluorescence since the dye is quenched by its proximity to the AuNP. Cleavage of the RNA by RNase A moves the fluorophores away from the AuNP, causing a signal increase. The same strategy was used to detect RNase $\mathrm{H}$, where the AuNPs were conjugated to DNA:RNA hybrids, with the RNA strand containing a fluorophore on one end (Fig. 3a). RNase $\mathrm{H}$ cleaves the RNA and increases the fluorescent signal while releasing the DNA. The detection sensitivity of this assay for RNase $\mathrm{H}$ and RNase A was $43 \mu \mathrm{U}$ and $0.73 \mathrm{fM}$ respectively for a reaction performed at $37{ }^{\circ} \mathrm{C}$.

$\mathrm{Li}$ and colleagues designed spherical nucleic acid probes where an AuNP core was coated with DNA:RNA duplexes (Fig. 3b). ${ }^{31}$
As the signal group, they used the two-photon fluorescent dye ethyl-4-[3,6-bis(1-methyl-4-vinyl-pyridium iodine)-9H-carbazol-9-yl] (EBMVC), which can be incorporated into the hydrophobic grooves of the DNA:RNA duplex through hydrogen bonding between EBMVC and the base pairs. ${ }^{38}$ In the presence of RNase $\mathrm{H}$, the RNA in the DNA:RNA duplex is cleaved, releasing the DNA strand and the bound EBMVC dye, causing an increase in fluorescence. This assay was specific to RNase $\mathrm{H}$ when tested against RNase HII, RNase A, and DNase I and had an LOD of $0.013 \mathrm{U} \mathrm{ml}^{-1}$. Further, the group also used this assay to characterize RNase $\mathrm{H}$ activity in cell lines such as HepG2, HeLa, L02 and MCF-7 as well as in rat liver tissue samples.

In another strategy using nanoparticles, Han and coworkers used DNAzymes for detecting RNase $\mathrm{H}$ activity, with an LOD of $0.00847 \mathrm{U} \mathrm{ml}^{-1}$ (Fig. 3c). ${ }^{32}$ AuNPs were conjugated with two sets of nucleic acid complexes. The substrate strands were single stranded DNA with a single ribonucleotide in the middle, and modified with a fluorophore at the terminal. The second type was a caged enzyme strand that contained a DNAzyme sequence. The DNAzyme sequence was hybridized to a complementary DNA strand, rendering it inactive. In the presence of RNase H, the RNA strand in a separate DNA:RNA initiation complex is cleaved, releasing the DNA strand. Through toe-hold mediated strand displacement reaction, this released DNA strand removes the DNA lock bound to the enzyme strand, thus activating the DNAzyme sequence. The DNAzyme sequence then interacts with the substrate strands on the AuNPs, cleaving the ribonucleotide sites and releasing fluorescent molecules. Subsequently, the DNAzyme strand moves to other substrate strands, generating a higher fluorescent signal. Chu and coworkers used a similar strategy for imaging intracellular RNase $\mathrm{H}$ activity in HeLa, MCF-7 and HepG2 cell lines. ${ }^{39}$ 


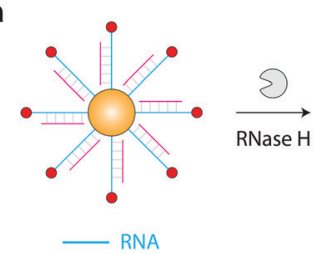

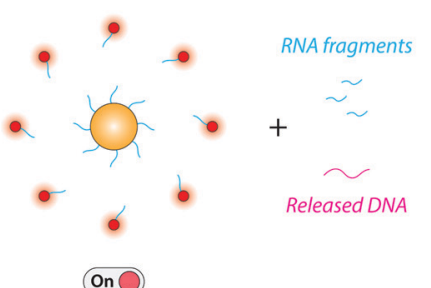

b
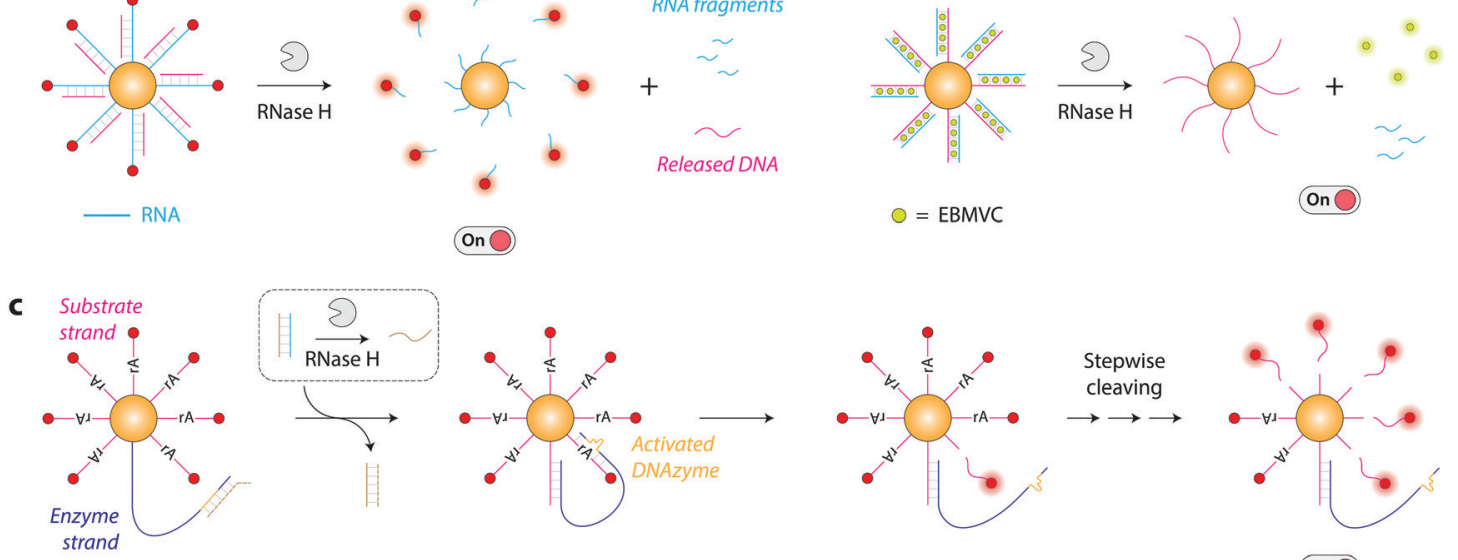

(OnO)
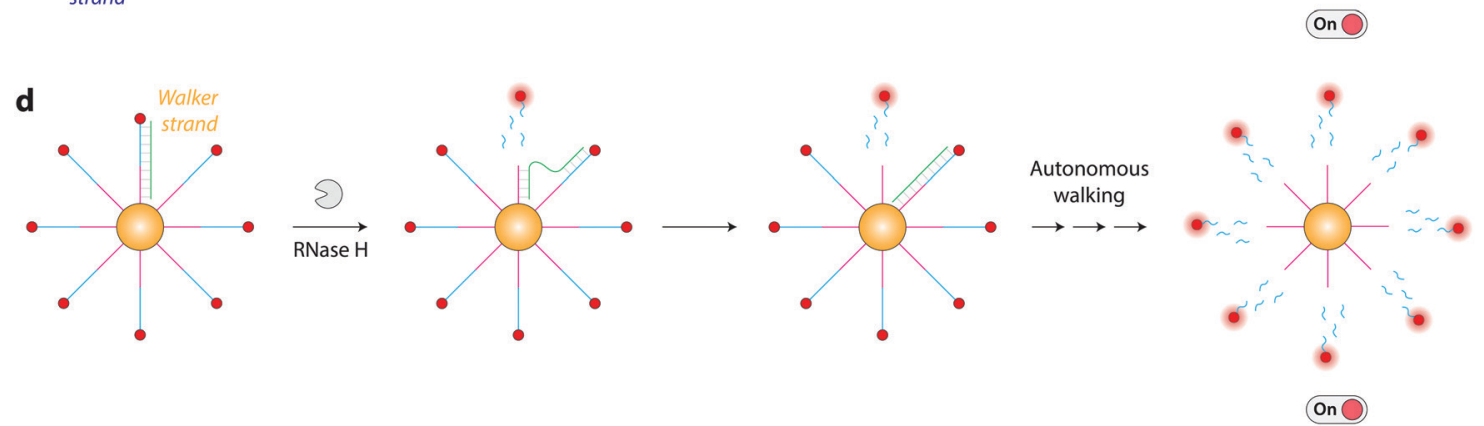

Fig. 3 DNA-nanoparticle assays for RNases. (a) Release of fluorophores from DNA-nanoparticle conjugates signals RNase activity. ${ }^{20}$ (b) DNA groove binders can be used as fluorescent moieties for RNase detection. ${ }^{31}$ (c) A nanoparticle conjugated DNAzyme acts on substrate strands to provide a signal. ${ }^{32}$ (d) DNA walker on a nanoparticle surface generates fluorescent signal indicating RNase H presence. ${ }^{22}$

Chu and coworkers also developed a signal amplification strategy based on an RNase H-powered DNA walking machine for detecting RNase $\mathrm{H}$ activity (Fig. $3 \mathrm{~d}$ ). ${ }^{22}$ This system consisted of AuNPs conjugated to DNA-RNA chimeric strands tagged with a fluorophore at the end. The walking DNA strand is complementary to this chimeric strand. RNase $\mathrm{H}$ cleaves the RNA segment of the duplex, releasing part of the DNA walker and the fluorophores in the process. The DNA walking strand then binds to a neighboring DNA-RNA chimeric strand, becoming the substrate for further RNase $\mathrm{H}$ activity. Thus, once activated, the DNA walker continues to move on the AuNP surface, releasing a fluorescently labeled RNA at every walking step. This method had an LOD of $0.035 \mathrm{U} \mathrm{ml}^{-1}$ and enabled RNase $\mathrm{H}$ detection in serum.

\subsection{DNA nanostructure-based assays}

DNA nanostructures have been used in detecting different types of biomarkers including enzymes. Specifically, DNA tetrahedra are often used because of their structural robustness, ${ }^{40}$ nuclease resistance ${ }^{41}$ and high cell penetration capability. ${ }^{42}$ These features also make them useful in biosensing, including RNase detection. Zhang et al. created a DNA tetrahedron that can report the presence of RNases using a photoinduced electron transfer (PET) mechanism..$^{33}$ They designed a DNA tetrahedron that contains a silver nanocluster (AgNC) on one of the strand termini and a G-quadruplex/hemin complex on another (Fig. 4a). In this PET process, the G-quadruplex/hemin complex promotes electron transfer from the AgNCs to the hemin $\mathrm{Fe}^{\mathrm{III}}$ center, thus resulting in a decrease in the fluorescence intensity of the AgNCs. The DNA tetrahedron also contained an RNA hairpin sequence on the vertex closer to the fluorescence complexes that can act as a trigger on recognizing RNase $\mathrm{H}$. They introduced an antisense oligonucleotide that can bind to the loop portion of the hairpin, which is then reacted on by RNase $\mathrm{H}$, cleaving the loop of the hairpin. The opening of the hairpin moves the AgNC and G-quadruplex/hemin complexes away from each other, causing fluorescence recovery of the AgNCs and signaling the presence of RNase $\mathrm{H}$. The LOD for this assay was $3.41 \mathrm{U} \mathrm{ml}^{-1}$.

In another study with DNA tetrahedron, Wang and coworkers modified one of the component strands to contain an rU base and tagged the strand with a fluorophore (FAM) and a quencher (BHQ1) at the $5^{\prime}$ and $3^{\prime}$ ends, respectively (Fig. 4b). ${ }^{34}$ On assembly, the fluorophore and quencher are in close proximity in the tetrahedron, thus quenching any fluorescence. RNase A cleaves the rU site, causing the tetrahedron to destabilize and the fluorophore and quencher to be separated, thus increasing the fluorescent signal. The RNase A concentration can be quantitatively monitored based on this fluorescent signal change, with an LOD of $0.09 \mathrm{pg} \mathrm{ml}^{-1}$. In addition, a natural compound G10 (a stimulator of RNase A) was used to amplify the fluorescence signal by upregulating the RNase A activity.

Dynamic DNA devices have also been used in detecting RNases. Halvorsen and colleagues used DNA nanoswitches that change conformation in response to RNases and detected 
a

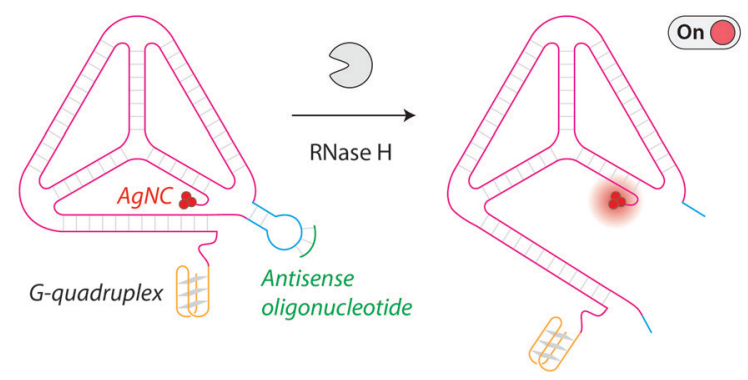

b

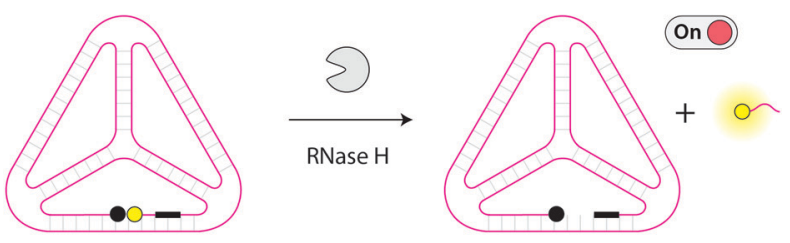

C
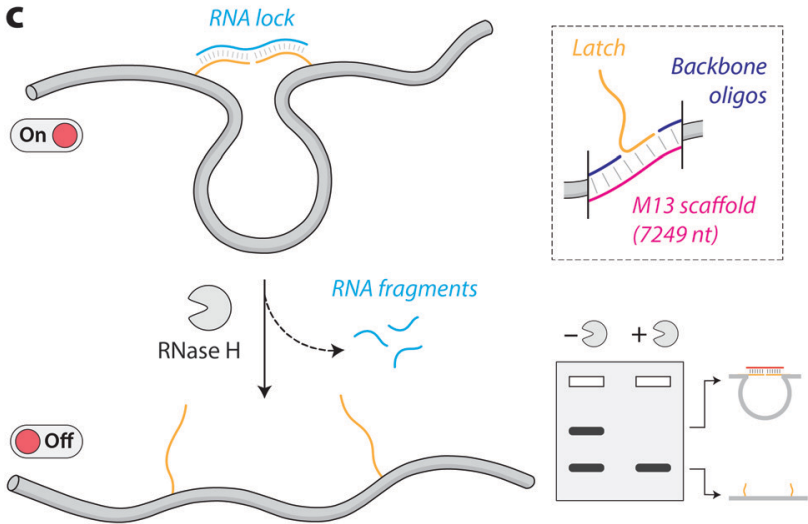

Fig. 4 DNA nanostructures for RNase detection. (a) and (b) show a DNA tetrahedron that produces a signal in the presence of RNases via photoinduced electron transfer ${ }^{33}$ and fluorescence, ${ }^{34}$ respectively. (c) DNA nanoswitches undergo a conformational change in the presence of RNase $\mathrm{H}$, with the change read out on agarose gel electrophoresis. ${ }^{35}$

enzyme presence using gel electrophoresis. ${ }^{35}$ The group used DNA nanoswitches locked by an RNA strand into a looped conformation (Fig. 4c). On the addition of RNase H, the RNA lock is digested, leading to release of DNA latches and opening of the nanoswitch into the linear conformation. This conformational change provided a direct gel-based readout of the RNase $\mathrm{H}$ activity where the signal is provided by the intercalation of regular DNA gel stains into the nanoswitch. This assay had an LOD of $0.02 \mathrm{U}$ in $10 \mu \mathrm{l}$ reaction. They also demonstrated RNase $\mathrm{H}$ response of the DNA nanoswitch in $10 \%$ serum and cell lysates with the assay performing efficiently at temperatures ranging from $4{ }^{\circ} \mathrm{C}$ to $37^{\circ} \mathrm{C}$.

\section{Screening inhibitors}

The importance of RNase assays extends beyond detecting contamination in biological samples and RNase biomarkers. The RNase $\mathrm{H}$ activity of HIV-1 reverse transcriptase is a required for retroviral DNA synthesis, thereby rendering this function an attractive target for anti-HIV therapeutics. ${ }^{43}$ In this context, several RNase $\mathrm{H}$ detection assays have been used to screen potential RNase $\mathrm{H}$ inhibitors. One of the most common RNase $\mathrm{H}$ inhibitors, ellipticine, is a small molecule that is reported to preferentially target DNA:RNA hybrids. The interaction of ellipticine with RNase $\mathrm{H}$ effectively inhibits enzymatic activity either by blocking enzyme binding or by interaction with the cleavage substrate.$^{44}$ In the literature discussed here, several assays were used to screen RNase $\mathrm{H}$ inhibitors such as ellipticine, ${ }^{19,28,32}$ ethidium bromide, ${ }^{28,29}$ gentamycin, ${ }^{22,29,30}$ oxoglaucine, ${ }^{19}$ streptomycin sulfate, ${ }^{22}$ kanamycin ${ }^{22,35}$ and ampicillin. ${ }^{22}$ Further analysis of the efficiency of RNase $\mathrm{H}$ inhibition could lead to promising drug development routes for AIDS treatment.

\section{Conclusion}

The new methods being developed for RNase detection address several limitations in earlier methods including laborious multistep processes and readouts that require expensive instrumentation. Several of the assays discussed here can efficiently detect RNases with high sensitivity and specificity. With such advancements, these strategies could fill an important need for identifying RNase contamination in biological samples and for characterizing RNase inhibitors. However, there are still some limitations that could be overcome with further development. For example, fluorescence and FRET techniques require labeled substrates, and might incur false signals due to nonspecific interactions. There is also a concern that the fluorescent groups might interfere with the kinetic behavior of assay. In nanoparticlebased assays, the need for functionalized thiol and dyemodified oligonucleotide probes add to the complexity, cost, and overall assay time of such detection strategies. However, recent developments in DNA-nanoparticle conjugation strategies might address this issue and aid in creating shelf-ready DNA-nanoparticle conjugates. DNA nanoswitches have an advantage in this regard since they do not require any labels or dyes. However, DNA nanoswitches require a gel read out, limiting its use in point-of-care, but could be combined with an optical readout for easier use.

Future research studies could comment on the practicality of the methods they develop, and the utility and shelf-life of the reagents used. This is especially important for these new assays to compete with RNase detection kits already available commercially. For example, knowledge of the stability of DNA structures or nanoparticles in solution would be useful to understand the shelf-life and on-site use of the particular method. Long term use might also necessitate dried storage of the reagents. The DNA nanoswitches discussed here were shown to efficiently detect RNases even when the nanostructure was dried and stored. ${ }^{35}$ This might be a challenge for nanoparticle-based assays since drying might result in aggregation of the particles. With several collective advantages, a combination of the strategies described here could result in a potential RNase detection kit that is viable for practical use and commercialization. 


\section{Conflicts of interest}

The author is an inventor on patent applications covering aspects of the DNA nanoswitch technology.

\section{References}

1 S. Sorrentino, Human extracellular ribonucleases: multiplicity, molecular diversity and catalytic properties of the major RNase types, Cell. Mol. Life Sci., 1998, 54, 785-794.

2 P. L. Boyer, S. J. Smith, X. Z. Zhao, K. Das, K. Gruber and E. Arnold, et al., Developing and Evaluating Inhibitors against the RNase H Active Site of HIV-1 Reverse Transcriptase, J. Virol., 2018, 92. Available from: https://jvi.asm.org/content/92/13/e02203-17.

3 D. H. Bechhofer and M. P. Deutscher, Bacterial ribonucleases and their roles in RNA metabolism, Crit. Rev. Biochem. Mol. Biol., 2019, 54, 242-300.

4 H. F. Rosenberg, RNase A ribonucleases and host defense: an evolving story, J. Leukocyte Biol., 2008, 83, 1079-1087.

5 P. A. Leland, L. W. Schultz, B.-M. Kim and R. T. Raines, Ribonuclease A variants with potent cytotoxic activity, Proc. Natl. Acad. Sci. U. S. A., 1998, 95, 10407-10412.

6 W. Huang, M. Zhao, N. Wei, X. Wang, H. Cao and Q. Du, et al., Site-Specific RNase A Activity Was Dramatically Reduced in Serum from Multiple Types of Cancer Patients, PLoS One, 2014, 9, e96490.

7 P. L. Xavier and A. R. Chandrasekaran, DNA-based construction at the nanoscale: emerging trends and applications, Nanotechnology, 2018, 29, 062001.

8 J. A. Hansen, R. Mukhopadhyay, J. Ø. Hansen and K. V. Gothelf, Femtomolar Electrochemical Detection of DNA Targets Using Metal Sulfide Nanoparticles, J. Am. Chem. Soc., 2006, 128, 3860-3861.

9 D. Zeng, Z. Wang, Z. Meng, P. Wang, L. San and W. Wang, et al., DNA Tetrahedral Nanostructure-Based Electrochemical miRNA Biosensor for Simultaneous Detection of Multiple miRNAs in Pancreatic Carcinoma, ACS Appl. Mater. Interfaces, 2017, 9, 24118-24125.

10 A. R. Chandrasekaran, M. MacIsaac, J. Vilcapoma, C. H. Hansen, D. Yang and W. P. Wong, et al., DNA Nanoswitch Barcodes for Multiplexed Biomarker Profiling, Nano Lett., 2021, 21, 469-475.

11 A. Porchetta, R. Ippodrino, B. Marini, A. Caruso, F. Caccuri and F. Ricci, Programmable Nucleic Acid Nanoswitches for the Rapid, Single-Step Detection of Antibodies in Bodily Fluids, J. Am. Chem. Soc., 2018, 140, 947-953.

12 W. Ji, D. Li, W. Lai, X. Yao, M. D. F. Alam and W. Zhang, et al., pH-Operated Triplex DNA Device on MoS2 Nanosheets, Langmuir, 2019, 35, 5050-5053.

13 S. Juul, F. Iacovelli, M. Falconi, S. L. Kragh, B. Christensen and R. Frøhlich, et al., Temperature-Controlled Encapsulation and Release of an Active Enzyme in the Cavity of a SelfAssembled DNA Nanocage, ACS Nano, 2013, 7, 9724-9734.

14 C. Mao, W. Sun, Z. Shen and N. C. Seeman, A nanomechanical device based on the B-Z transition of DNA, Nature, 1999, 397, 144-146.
15 S. Sato and S. Takenaka, Highly Sensitive Nuclease Assays Based on Chemically Modified DNA or RNA, Sensors, 2014, 14, 12437-12450.

16 P. Frank, C. Cazenave, S. Albert and J. J. Toulme, Sensitive Detection of Low Levels of Ribonuclease $\mathrm{H}$ Activity by an Improved Renaturation Gel Assay, Biochem. Biophys. Res. Commun., 1993, 196, 1552-1557.

17 H. H. Hogrefe, R. I. Hogrefe, R. Y. Walder and J. A. Walder, Kinetic analysis of Escherichia coli RNase H using DNA-RNADNA/DNA substrates, J. Biol. Chem., 1990, 265, 5561-5566.

18 X. Xie, W. Xu, T. Li and X. Liu, Colorimetric Detection of HIV-1 Ribonuclease H Activity by Gold Nanoparticles, Small, 2011, 7, 1393-1396.

19 C. Y. Lee, H. Jang, K. S. Park and H. G. Park, A label-free and enzyme-free signal amplification strategy for a sensitive RNase $\mathrm{H}$ activity assay, Nanoscale, 2017, 9, 16149-16153.

20 J. H. Kim, R. A. Estabrook, G. Braun, B. R. Lee and N. O. Reich, Specific and sensitive detection of nucleic acids and RNases using gold nanoparticle-RNA-fluorescent dye conjugates, Chem. Commun., 2007, 4342-4343.

21 S. Persano, G. Vecchio and P. P. Pompa, A hybrid chimeric system for versatile and ultra-sensitive RNase detection, Sci. Rep., 2015, 5, 1-5.

22 Y. Wang, N. Hu, C. Liu, C. Nie, M. He and J. Zhang, et al., An RNase H-powered DNA walking machine for sensitive detection of RNase $\mathrm{H}$ and the screening of related inhibitors, Nanoscale, 2020, 12, 1673-1679.

23 Y. Zhang, Z. Li, Y. Cheng and X. Lv, Colorimetric detection of microRNA and RNase $\mathrm{H}$ activity in homogeneous solution with cationic polythiophene derivative, Chem. Commun., 2009, 3172-3174.

24 Y. Jung, C. Y. Lee, K. S. Park and H. G. Park, Target-Activated DNA Polymerase Activity for Sensitive RNase $\mathrm{H}$ Activity Assay, Biotechnol. J., 2019, 14, 1800645.

25 L. Wang, H. Zhou, B. Liu, C. Zhao, J. Fan and W. Wang, et al., Fluorescence Assay for Ribonuclease $\mathrm{H}$ Based on Nonlabeled Substrate and DNAzyme Assisted Cascade Amplification, Anal. Chem., 2017, 89, 11014-11020.

26 C. Tong, T. Zhou, C. Zhao, L. Yuan, Y. Xu and B. Liu, et al., Fluorometric determination of RNase $\mathrm{H}$ via a DNAzyme conjugated to reduced graphene oxide, and its application to screening for inhibitors and activators, Microchim. Acta, 2019, 186, 335.

27 C. Y. Lee, K. S. Kang, K. S. Park and H. G. Park, Determination of RNase $\mathrm{H}$ activity via real-time monitoring of targettriggered rolling circle amplification, Microchim. Acta, 2017, 185, 53.

28 D. $\mathrm{Hu}$, F. Pu, Z. Huang, J. Ren and X. Qu, A QuadruplexBased, Label-Free, and Real-Time Fluorescence Assay for RNase H Activity and Inhibition, Chem. - Eur. J., 2010, 16, 2605-2610.

29 K. Wu, C. Ma, H. Liu, H. He, W. Zeng and K. Wang, Labelfree fluorescence assay for rapid detection of RNase $\mathrm{H}$ activity based on Tb3 + -induced G-quadruplex conjugates, Anal. Methods, 2017, 9, 3055-3060. 
30 K. Wu, C. Ma, Z. Deng, N. Fang, Z. Tang and X. Zhu, et al., Label-free and nicking enzyme-assisted fluorescence signal amplification for RNase $\mathrm{H}$ determination based on a G-quadruplexe/thioflavin T complex, Talanta, 2018, 182, 142-147.

31 N. Wang, L. Song, H. Xing, K. Zhang, R. Yang and J. Li, A spherical nucleic acid-based two-photon nanoprobe for RNase $\mathrm{H}$ activity assay in living cells and tissues, Nanoscale, 2019, 11, 8133-8137.

32 W. Wang, M. Shu, A. Nie and H. Han, Ultrasensitive evaluation of Ribonuclease $\mathrm{H}$ activity using a DNAzymepowered on-particle DNA walker, Sens. Actuators, B, 2020, 304, 127380.

33 K. Zhang, W. Huang, Y. Huang, H. Li, K. Wang and X. Zhu, et al., DNA Tetrahedron Based Biosensor for Argonaute2 Assay in Single Cells and Human Immunodeficiency Virus Type-1 Related Ribonuclease H Detection in Vitro, Anal. Chem., 2019, 91, 7086-7096.

34 C. Tong, Y. Hu, Q. Xie, T. Zhou, J. Fan and Y. Qin, et al., Sensitive RNase A detection and intracellular imaging using a natural compound-assisted tetrahedral DNA nanoprobe, Chem. Commun., 2020, 56, 3229-3232.

35 A. R. Chandrasekaran, R. Trivedi and K. Halvorsen, Ribonuclease-Responsive DNA Nanoswitches, Cell Rep. Phys. Sci., 2020, 1, 100117.

36 H. Arthanari, S. Basu, T. L. Kawano and P. H. Bolton, Fluorescent dyes specific for quadruplex DNA, Nucleic Acids Res., 1998, 26, 3724-3728.
37 B. Li, A. D. Ellington and X. Chen, Rational, modular adaptation of enzyme-free DNA circuits to multiple detection methods, Nucleic Acids Res., 2011, 39, e110.

38 Y. Zhang, J. Wang, P. Jia, X. Yu, H. Liu and X. Liu, et al., Twophoton fluorescence imaging of DNA in living plant turbid tissue with carbazole dicationic salt, Org. Biomol. Chem., 2010, 8, 4582-4588.

39 N. Hu, Y. Wang, C. Liu, M. He, C. Nie and J. Zhang, et al., An enzyme-initiated DNAzyme motor for RNase $\mathrm{H}$ activity imaging in living cell, Chem. Commun., 2020, 56, 639-642.

40 M. L. J. Carter, D. A. Rusling, S. Gurr, T. Brown and K. R. Fox, Stability of the different arms of a DNA tetrahedron and its interaction with a minor groove ligand, Biophys. Chem., 2020, 256, 106270.

41 J.-W. Keum and H. Bermudez, Enhanced resistance of DNAnanostructures to enzymatic digestion, Chem. Commun., 2009, 7036-7038.

42 A. S. Walsh, H. Yin, C. M. Erben, M. J. A. Wood and A. J. Turberfield, DNA Cage Delivery to Mammalian Cells, ACS Nano, 2011, 5, 5427-5432.

43 E. Tramontano and R. D. Santo, HIV-1 RT-Associated RNase H Function Inhibitors: Recent Advances in Drug Development, Curr. Med. Chem., 2010, 17, 2837-2853.

44 J. Ren, X. Qu, N. Dattagupta and J. B. Chaires, Molecular Recognition of a RNA:DNA Hybrid Structure, J. Am. Chem. Soc., 2001, 123, 6742-6743. 